\title{
Feature Extraction for the Discrimination of Crop and Weed in Digital Images using Open CV and Python
}

\author{
Senthilkumar K., Sathiyaraj Subramaniyam, Sharmila S., Illakiah H. R.
}

\begin{abstract}
Variable rate herbicide spraying technology has become integral part of precision agriculture and this system works based on the weed density map of agriculture field. To improve the accuracy of crop/weed discrimination process this paper presents different image processing techniques. Edge detection process for obtaining contour is performed by using sobel operator with 5X5 gradient operator and canny edge detector. Grayscale morphological operations are performed to remove gray overlap due to background of the image in order to improve the accuracy of the segmentation process. In order to check the discrimination accuracy and extracting image features, the experiment was performed on 100 images of maize plant and weed plant leaves. From the experimental results, it is concluded that the proposed method can accurately extract leaf parameters for discrimination process with soil background.
\end{abstract}

Keywords : Edge detection, Gray scale morphology, crop/weed discrimination, Image features, Image classification

\section{INTRODUCTION}

Agriculture is the most important part of indian economy, many indians depends on farming for their food and life. In agriculture practices precision farming will become the future trend. In modern agriculture development traditional practices are no longer suited. Weed plants are the main threat to the crop yield. Depending on type of crop and soil there are wide varities of weed in agriculture field. The weed plant have narrow or broad leaves and also present in inter row or inter column in agriculture field. They are interrupting the growth of the crop by competiting in resource sharing manner like water, sunlight and fertilizer, etc,. This will reduce the quality and quantity of agriculture yield. Traditional practice for weed detection and removal is generally a manual labor method. This method is done by

Revised Manuscript Received on February 05, 2020.

* Correspondence Author

Senthilkumar $\mathbf{K}^{*}$., Department of Mechatronics Engg, Coimbatore Institute of Engg and Technology, Coimbatore, Tamilnadu, India.

Email: rkssenkumar@gmail.com

Sathiyaraj Subramaniyam, Department of Crop Physiology Adhiyaman College of Agriculture and Research, Tamilnadu, India. Email: sakkthi18@gmail.com

Sharmila S., Department of Mechatronics Engg, Coimbatore Institute of Engg and Technology, Coimbatore, Tamilnadu, India. Email: sharmilashivaswamy@gmail.com

Illakiah HR, Department of Mechatronics Engg, Coimbatore Institute of Engg and Technology, Coimbatore, Tamilnadu, India. Email: illakiahhr@gmail.com

(C) The Authors. Published by Blue Eyes Intelligence Engineering and Sciences Publication (BEIESP). This is an open access article under the CC BY-NC-ND license (http://creativecommons.org/licenses/by-nc-nd/4.0/) manual removal of weeds, mechanical weeder and using chemical herbicide. Herbicide application plays major role in weed control and management but its excessive usage results harmful effect on human beings. Weed control and management is one of agriculture practices which demands automation. In conventional or manual method the required herbicide is sprayed uniformly all over the crop fields. It results negative impact on soil and plant, also more amount of herbicide will be wasted as only some parts of field covered with weed plant. In order to prevent these possibilities from happening an intelligent weed detection and recognition system need to be developed. These smart systems should have the capability of locating the weed plants and to activate the herbicide sprayer to spray the chemical on the target weed plant. Recent research activities are focused on plant classification based on components such as flowers, leaves, stems and barks. Color properties of potato leaf is used as a discriminative factor for weed density measurement is presented in [1]. For detecting weed plants erosion and dilation based image processing operations are performed in [2]. In India maize is the most important field crop successful cultivation of it depends on efficacy of weed control. Acalypha indica is one of the predominant weed present in maize crop field. In order to perform effective weed control the first critical process is weed identification. In [3] plant classification method is proposed based on leaf vein and shape. Plant leaf recognition [4] and classification depends on two important features such as leaf shape and color. The proposed method presents image processing methodology to perform crop/weed discrimination process.

\section{METHODOLOGY}

Agriculture field image usually contains three elements soil, crop plants and weed plants. Literature proposes weed detection method is divided into three steps namely segmentation process of background, crop elimination and extraction of weed plant. Weed identification is one of the process of distinguishing weeds and crops in agriculture field image. In order to improve the detection accuracy more effective image processing techniques needs to be used. Morphological operations are performed to extract the patterns in different forms from the crop/weed leaf images. Image contour features are highly suitable for plant classification and localization problems.

The Proposed method is implemented using python with open CV on raspberry pi processor. The flow of operation is illustrated below. 

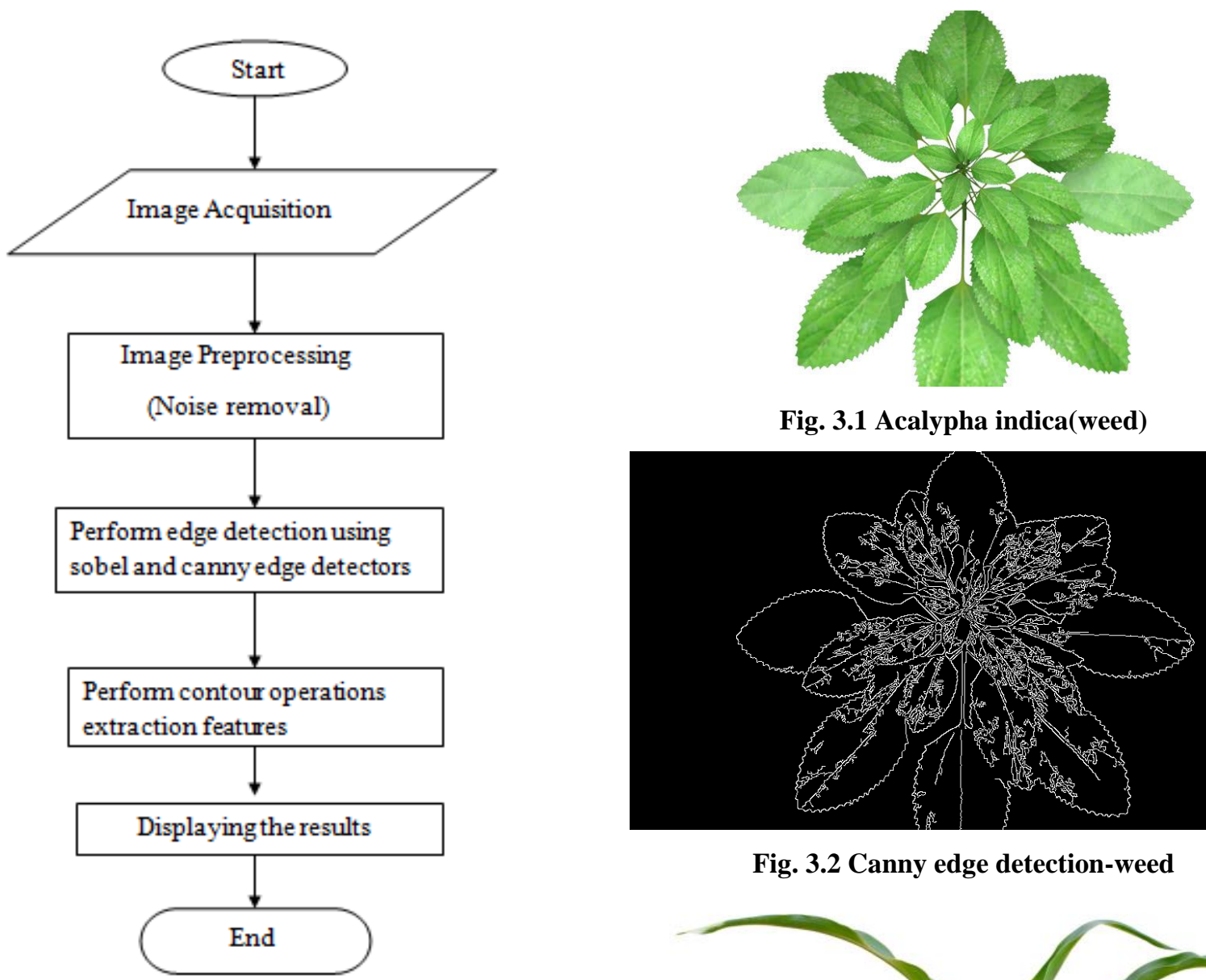

Fig. 3.1 Acalypha indica(weed)

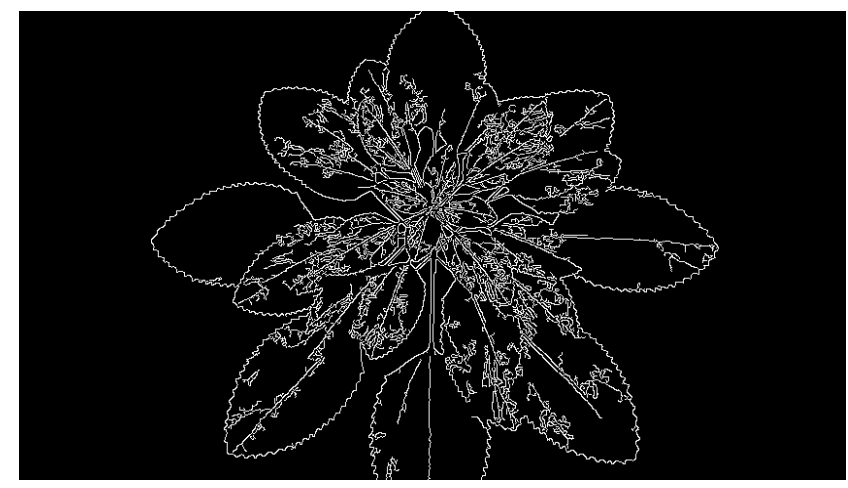

Fig. 3.2 Canny edge detection-weed

\section{IMAGE PROCESSING OPERATIONS USING OPEN CV SOFTWARE}

\section{A. Adaptive thresholding}

Algorithm:

(i) An $\mathrm{n} \mathrm{X} n$ region is selected in the given image

(ii) Calculated the weighted average or Gaussian weighted average of the pixels WA(x,y)

(iii) Find the required threshold $\mathrm{T}(\mathrm{x}, \mathrm{y})$ by subtracting a constant parameter(P1).

$$
\mathrm{T}(\mathrm{x}, \mathrm{y})=\mathrm{WA}(\mathrm{x}, \mathrm{y})-\mathrm{P} 1
$$

\section{B. Canny edge detection}

Algorithm:

(i) Using 5x5 Gaussian filter to remove high frequency noise

(ii) Calculate intensity gradient

Edge gradient (edge strength) $(\mathrm{G})=\sqrt{G_{x}^{2}+G_{y}^{2}}$

Edge direction or Angle $(\theta)=\tan ^{-1}\left(\frac{G_{y}}{G_{x}}\right)$

(iii) Remove "false" responses by applying non-maximum suppression

(iv) Using lower and upper boundary on the gradient values to perform thresholding operation

(v) Using hysteris to track the edges 


\section{Edge detection using sobel operator}

Usually the leaves of a plant are usually overlap with each other, so that edge detection process for detecting leaf shape is become's a complex process. The Edge detection operator significantly reduces the amount of data to be processed which further helps to identify and locate the contours. In this research work various weight matrices obtained from pascal triangle theory is used for implementing sobel operator for edge detection.

Sobel operators weight matrices:

$$
\left|\begin{array}{ccccc}
1 & 4 & 6 & 4 & 1 \\
2 & 8 & 12 & 8 & 2 \\
0 & 0 & 0 & 0 & 0 \\
-2 & -8 & -12 & -8 & -2 \\
-1 & -4 & -6 & -4 & -1
\end{array}\right|
$$$$
\begin{gathered}
{\left[\begin{array}{ccccc}
6 & 4 & 1 & 2 & 0 \\
4 & 12 & 8 & 0 & -2 \\
1 & 8 & 0 & -8 & -1 \\
2 & 0 & -8 & -12 & -4 \\
0 & -2 & -1 & -4 & -6
\end{array}\right]} \\
45^{\circ} \text { edge direction }
\end{gathered}
$$$$
\left.\begin{array}{ccccc}
1 & 2 & 0 & -2 & -1 \\
4 & 8 & 0 & -8 & -4 \\
6 & 12 & 0 & -12 & -6 \\
4 & 8 & 0 & -8 & -4 \\
1 & 2 & 0 & -2 & -1
\end{array}\right]
$$

\section{Gray level morphological operations}

Morphological operations are performed on the image $f(x, y)$ with structured element $b$.

(i) Erosion

$$
\begin{array}{r}
(f \Theta b)(s, t)=\min \{f(s+x, t+y)-b(x, y) \mid \\
\left.(s+x, t+y) \in D_{f},(x, y) \in D_{b}\right\}
\end{array}
$$

(ii) Dilation

$$
\begin{array}{r}
(f \oplus b)(s, t)=\max \{f(s+x, t+y)+b(x, y) \mid \\
\left.(s+x, t+y) \in D_{f},(x, y) \in D_{b}\right\}
\end{array}
$$

(iii) Opening

$$
f \circ b=(f \Theta b) \oplus b
$$

(iv) Closing

$$
f \bullet b=(f \oplus b) \Theta b
$$

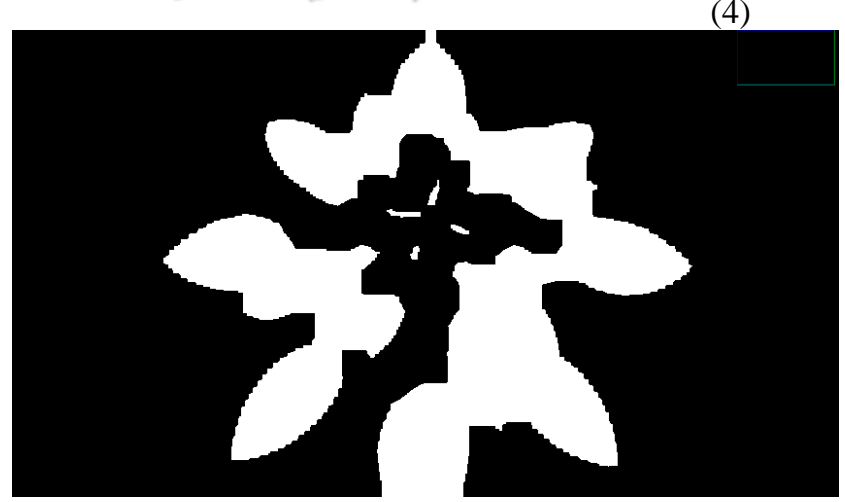

Fig. 3.5 Morphology-erosion

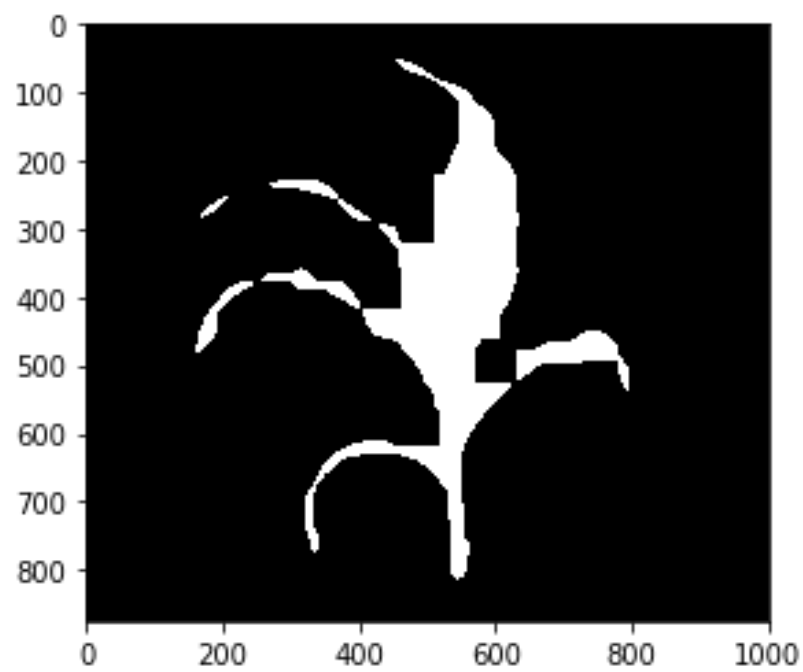

Fig. 3.6 Morphology-closing

\section{E. Contour feature extraction}

Different contour functions performed on the crop image is presented below.

(i) Moment (m)

It is used to find center of the leaf and also used to estimate the leaf area.

Centroid is given by $\mathrm{C}_{\mathrm{x}}=[\mathrm{m} 10 / \mathrm{m} 00]$ and $\mathrm{C}_{\mathrm{y}}=[\mathrm{m} 01 / \mathrm{m} 00]$

(ii) Contour area and contour perimeter calculation

(iii) Approximation for contour shape

(iv) Bounding rectangle construction for identifying different leaves.

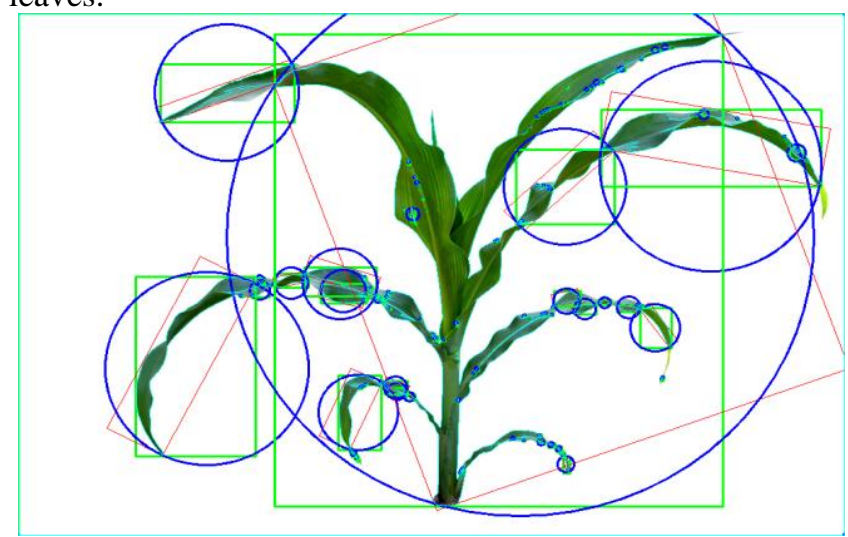

Fig. 3.7 Contour - crop

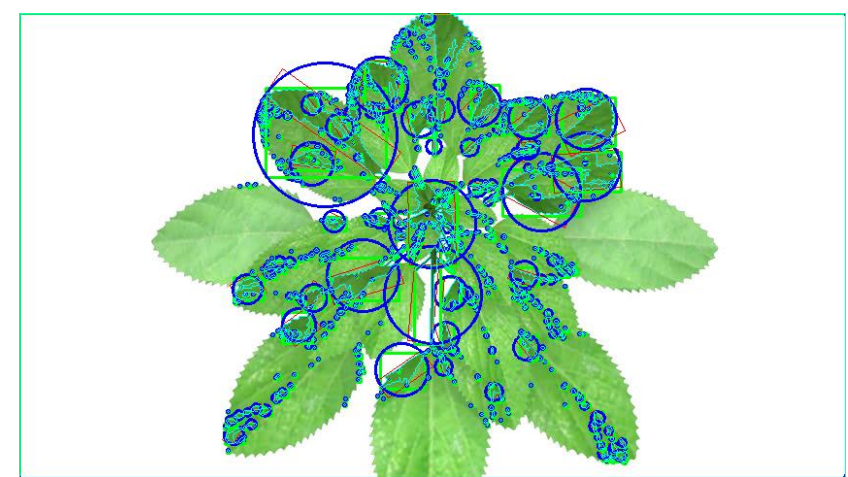

Fig. 3.8 Contour - weed

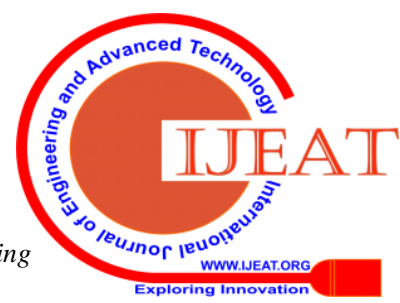




\section{LEAF FEATURE EXTRACTION}

Plant classification is the key issue to be addressed for weed /crop leaf recognition. In this paper the leaf contour extraction process is carried out by using gradient information. Before leaf contour extraction process the following steps to be carried out,

(i)Image preprocessing

(ii) Using OTSU thresholding convert the given gray scale image into binary image

(iii) Using eight direction chain codes to extract the contour of the leaf

In this work the Euclidian distance between the contour and the center point is also used to outline the contour.

Otsu's Binarization:

Steps:

(i) Obtain the histogram of the given image

(ii) Setting up weights and means corresponding to the zero threshold value

(iii) Looping through all the threshold value and update the weights, mean and calculate class variance

(iv) Threshold value is chosen based on maximum variance The simulation results of Otsu's Binarization are presented in figure 4.1 and 4.2 .

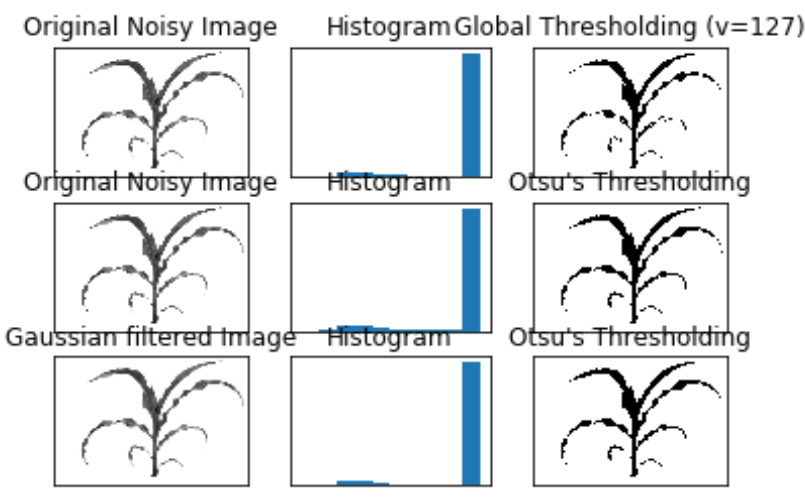

Fig. 4.1 Ostu thresholding results-maize

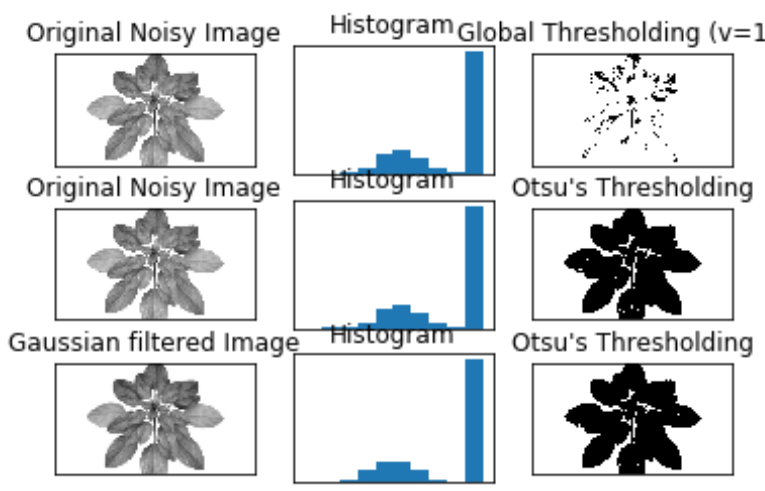

Fig 4.2 Ostu thresholding- weed

The mathematical expressions used to obtain mean and variance are presented below.

$$
\begin{aligned}
& q_{1}(t)=\sum_{i=1}^{t} P(i) \quad \& \quad q_{1}(t)=\sum_{i=t+1}^{I} P(i) \\
& \mu_{1}(t)=\sum_{i=1}^{t} \frac{i P(i)}{q_{1}(t)} \quad \& \quad \mu_{2}(t)=\sum_{i=t+1}^{I} \frac{i P(i)}{q_{2}(t)}
\end{aligned}
$$

$$
\sigma_{1}^{2}(t)=\sum_{i=1}^{t}\left[i-\mu_{1}(t)\right]^{2} \frac{P(i)}{q_{1}(t)} \quad \& \quad \sigma_{2}^{2}(t)=\sum_{i=t+1}^{I}\left[i-\mu_{1}(t)\right]^{2} \frac{P(i)}{q_{2}(t)}
$$

Generally there are three approaches for weed classification and detection namely shape based, color and texture analysis. Image features extracted from weed and crop images are presented below in Table I, II and III.

Table- I: Contour features

\begin{tabular}{|c|c|c|c|}
\hline $\begin{array}{c}\text { S.n } \\
\mathbf{0}\end{array}$ & Feature & $\begin{array}{c}\text { Crop- } \\
\text { Maize plant }\end{array}$ & $\begin{array}{c}\text { Weed- } \\
\text { Acalypha } \\
\text { indica }\end{array}$ \\
\hline 1 & Moments & 120 & 187 \\
\hline 2 & Contour Area & 387 & 544 \\
\hline 3 & Perimeter & 5.6 & 8.2 \\
\hline 4 & $\begin{array}{c}\text { Length of } 1^{\text {st }} \\
\text { Contour }\end{array}$ & 135 & 54 \\
\hline 5 & $\begin{array}{c}\text { Eccentricity } \\
\text { Aspect Ratio }\end{array}$ & 10 & 2.3 \\
\hline 6 & 1.4 & 1.5 \\
\hline 7 & Rectangularity & 3.7 & 0.0087 \\
\hline 8 & Circularity & 34.7 & 30.17 \\
\hline 9 & $\begin{array}{c}\text { Equivalent } \\
\text { Diameter }\end{array}$ & 22.1 & 258 \\
\hline
\end{tabular}

Table- II: Color based features

\begin{tabular}{|l|l|c|c|}
\cline { 2 - 4 } \multicolumn{1}{c|}{} & Maize & Weed & \multicolumn{1}{c|}{245} \\
\hline \multirow{4}{*}{ Mean } & B-Mean & 241 & 230 \\
\cline { 2 - 4 } Variance & G-Mean & 247 & 204 \\
\cline { 2 - 4 } & R-Mean & 245 & 54 \\
\cline { 2 - 4 } & B-Variance & 52 & 35 \\
\cline { 2 - 4 } & G-Variance & 27 & 67 \\
\cline { 2 - 4 } & R-Variance & 37 & \\
\hline
\end{tabular}

Table- III: Texture based features

\begin{tabular}{|l|c|c|}
\cline { 2 - 3 } \multicolumn{1}{c|}{} & Maize & Weed \\
\hline Contrast & 127 & 158 \\
\hline Correlation & 0.98 & 0.78 \\
\hline $\begin{array}{l}\text { Inverse Difference } \\
\text { Moments }\end{array}$ & 0.6 & 0.5 \\
\hline Entropy & 5.8 & 5.4 \\
\hline
\end{tabular}

\section{RESULT ANALYSIS}

In order to test and evaluate our proposed method, 100 images of different weeds and crops are used. The image processing operations like adaptive thresholding and edge detection are essential for leaf feature extraction.

Published By:

Blue Eyes Intelligence Engineering

\& Sciences Publication 
The edge detection process described in chapter III provides better results. The filters and operators implemented in this project can effectively extract the useful contour features for weed/crop classification. Three most important factors to be considered for feature extraction are (i) crop type (ii) weed species type (iii) soil background. The threshold value and edge features needs to be adjusted according to the factors mentioned above to get better results. As can be seen in table I,II and III the algorithm presented in chapter III can extract the useful image features for discrimination process. But when more number of weeds in a crop filed the accuracy of the proposed methodology tend to decrease. This research work is the preliminary study to extract and tabulate important features, also needs further operation to improve the efficiency and accuracy.

\section{CONCLUSION:}

This research paper proposed a method for discriminating maize crop plant and weeds in agriculture field. Using the shape, color, and texture descriptors results obtained from the experiments, the discrimination process is easily carried out by using classification algorithms. The proposed method works well when the crops and weeds present in its initial stage of growth. If the crop is further developed, the weeds are present in the overlapping manner and the image classification operation is become complex and difficult.

\section{REFERENCES:}

1. Amir HKB \& Ali MS, "Automatic Weed Detection System and Smart Herbicide Sprayer Robot for corn fields”, IEEE Int. Conf. on Robotics and Mechatronics, Tehran, (2013), pp.468-473.

2. Muhammad HS, Irshad A \& Suziah BS, "Weed Recognition Based on Erosion and Dilation Segmentation Algorithm", Int. Conf. on Education Technology and Computer, Singapore, (2009), pp.224-228.

3. K. Lee and K. Hong, "An Implementation of Leaf Recognition System using Leaf Vein and Shape," International Journal of Bio-Science and BioTechnology, vol. 5, no. 2, April 2013.

4. J. H. Kim, R. G. Huang, S. H. Jin and K. S. Hong, "Mobile-based flower recognition system", 2009 Third International Symposium on Intelligent Information Technology Application , (2009), NanChang, China.

5. J.-X. Du, X.-F. Wang, and G.-J. Zhang, "Leaf shape based plant species recognition," Applied Mathematics and Computation, 2007, vol. 185.

6. Prof. Sanjay B. Dhaygude, Mr.Nitin P.Kumbhar "Agricultural plant Leaf Disease Detection Using Image Processing” International Journal of Advanced Research in Electrical, Electronics and Instrumentation Engineering,2013 Vol. 2, Issue 1.

7. Mahmood R. Golzarian and Ross A. Frick, "Segmentation of Cereal Plant Images Using Level Set Methods - A Comparative Study", International Journal of Information and Electronics Engineering, 2011.

\section{AUTHORS PROFILE}

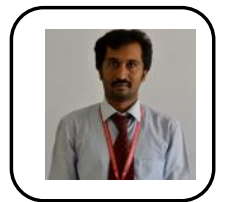

Mr.Senthilkumar K., is working as an Assistant professor at Coimbatore Institute of Engineering and Technology since 2012. He has teaching and industrial experience of ten years. In addition to hands on experience, he has several publications in Internal and National renowned journals and conferences.

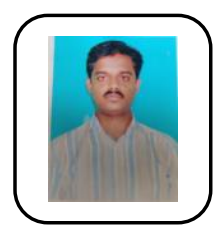

Sathiyaraj Subramaniyam K., is working as an Assistant professor (Crop Physiology) at Adhiyaman College of Agriculture and Research, Krishnagiri since 2017. He has teaching and industrial experience of five years. He is involved in several sponsored projects and consultancy projects.

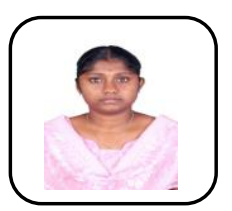

Sharmila.S is working as an Assistant professor at Coimbatore Institute of Engineering and Technology since 2018. She has teaching and industrial experience of four years. In addition to hands on experience, She has 5 publications in international and national journals and conferences.

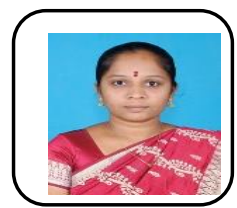

Illakiah HR is working as an Assistant professor a Coimbatore Institute of Engineering and Technology since 2019. She has teaching and industrial experience of eight years. She has research interest in electrical machines, control systems and solar energy. 